\title{
Fuzzy Risk Prioritization of the Failure Modes in Rolling Stocks
}

\author{
B. Ghodrati ${ }^{1}$, M.J. Rahimdel ${ }^{2}$, A. Taghizadeh Vahed ${ }^{1}$ \\ ${ }^{1}$ Division of Operation and Maintenance Engineering, Lulea University of Technology, Lulea, Sweden \\ ${ }^{2}$ Department of Mining Engineering, Sahand University of Technology, Tabriz, Iran \\ (m_rahimdel@sut.ac.ir)
}

\begin{abstract}
Failure Mode and Effects Analysis (FMEA) is extensively used to identify and eliminate the potential failures in products, processes, designs, and services. In this approach, the detectability, occurrence and the severity of each identified failure mode need to be determined usually by a FMEA team. This paper aims to prioritize the failure modes of rolling stocks by integrating Analytical Hierarchy Process (AHP) and Risk Priority Number (RPN). To reduce the uncertainties and ambiguities, all calculations are done in the fuzzy environment instead of the crisp values. The importance degree of each failure mode is determined and then the overall fuzzy RPN is calculated. In this way, the critical failure modes are defined to make an efficient maintenance decision.
\end{abstract}

Keywords - Rolling stock, FMEA, AHP, fuzzy set

\section{INTRODUCTION}

Railway transportation is one of the must usual passenger and freight transferring system in many countries. Rolling stock, refer to all the vehicles that move on a railway, is the most important component of the rail transport system to affect the efficiency and long operation life of the railway transportation. In-operation failures of the rolling stocks result in transportation delays and therefore, knowledge of the failure modes and causes and accordingly considering the preventive maintenance activities is essential.

Nowadays, some studies have been done in the field of failure analysis of rolling stocks. For example, Seo et al. [1] studied the prototype electrical traction system of a Korea electric High Speed Train (KHST) using failure mode analysis. Results of this study showed that the train control, data transmission and electric traction were the most importance subsystem of train. The pantograph and motor block had the highest failure rate among all subsystems. Conradie and Treurnicht [2] studied inservice failures of rolling stock in South African Passenger Rail Company to determine the contribution of different failure modes. Regarding the results of that study, about $25 \%$ of the travel cancellations caused by the rolling stock department. $85 \%$ of delays caused due to failures in electrical control equipment, high voltage and switch equipment and traction/axillary machines and controls. In the other research, Fourie et al. [3] identified the reliability block diagram for three motor coach sets of passenger rail service of South Africa in the form of four main subsystems including power generation, compressed air, vacuum and propulsion systems. As the results of this study, the axillary equipment had the lowest reliability while, the compressor and vacuum exhauster had the most reliable components.

The past studies, some of them were mentioned above, have usually focused on specific part/systems of the locomotive and the validation of results only done in rare cases. These researches have not been taken into account all possible failure modes and also the important degree of them in the both technical and economical points of view. Moreover, vagueness and uncertainties judgment of human being in such decision problems persuade us to apply the efficient decision making model [4]. In these points of view, this study aims to use the Failure Mode and Effect Analysis (FMEA), as an effective and wellknown method, to identify all potential failure modes of rolling stocks of the LKAB company in Sweden. To achieve this goal, first the main failure modes of the wheel set subsystem, as the main cause of the rolling stocks failures, is considered. The Analytical Hierarchy Process (AHP) is used to determine the importance degree of the failure modes and then the overall Risk Priority Number (RPN) is calculated to prioritize the various failure modes. To reduce the uncertainties and ambiguities, all calculations are done in the fuzzy environment.

Results of this study, will be helpful for engineers, managers and technical directors to know the critical failures and select the efficient maintenance plan.

The organization of the paper is summarized as follows. In section 2 of the paper, the fuzzy AHP and then the fuzzy RPN are presented and then in section 3, the mentioned approach is applied to calculate the fuzzy overall PRN.

\section{METHODOLOGY}

In this section, first, the fuzzy AHP method is introduced to calculate the importance degree of failure modes and then, the overall RPN in the fuzzy environment is presented.

Zadeh [5] represented a new approach based on the generalization of the standard set theory to the fuzzy sets. A crisp set only allows full membership or no membership at all while the fuzzy set, allows partial membership. Zadeh proposed the use of values ranging from zero to one to show the object's membership in a fuzzy set. The complete non-membership and membership are represented by zero and one, respectively. Values between zero and one indicate the 
intermediate membership degrees. The fuzzy set is characterized by a membership function, which assigns to each object a grade of membership ranging between zero and one. Triangular Fuzzy Numbers (TFNs) are expressed with $\tilde{M}=(l, m, u)$ in which the parameter $l$ indicates the smallest possible value and $m$ and $u$, respectively, represent the most promising and the largest possible value $[4,6]$.

\section{AHP method in the fuzzy environment}

The AHP, which was first presented by Saaty [7], is based on the innate human ability to make judgments about small problems. In the conventional AHP, the pairwise comparisons for each level regarding the customer's satisfaction are directed using the point scales [8]. The pairwise comparisons ratio in the real crisp numbers are usually linguistic and vague. The human assessments in this way are imprecise and cannot really reflect the human thinking style. To overcome this kind of uncertainty, the fuzzy AHP was developed.

Steps of the AHP method in the fuzzy environment introduced by Chang [9] are summarized as follows:

Step 1: Constructing the triangular Fuzzy Judgment Matrix Construction

By using TFNs via pairwise comparison, the fuzzy judgment matrix $\tilde{A}=\left(a_{i j}\right)$ can be expressed mathematically as:

$$
\widetilde{A}=\left[\begin{array}{cccc}
1 & \tilde{a}_{12} & \mathrm{~K} & \tilde{a}_{1 n} \\
\tilde{a}_{21} & 1 & \mathrm{~K} & \tilde{a}_{2 n} \\
\mathrm{M} & \mathrm{M} & 1 & \mathrm{M} \\
\tilde{a}_{n 1} & \tilde{a}_{n 2} & \mathrm{~K} & 1
\end{array}\right]
$$

The judgment matrix $\tilde{A}$ is an $n \times n$ fuzzy matrix containing fuzzy numbers $\tilde{a}_{i j}$ and $\tilde{a}_{j i}=1 / \tilde{a}_{i j}$. Regarding the uncertainties in human idea about the fuzzy linguistic variables, including very important to very high, the fuzzy numbers in correspond of each linguistic variable are given in Table I.

TABLE I

LINGUISTIC VARIABLES AND THEIR CORRESPONDING TFN

\begin{tabular}{lcc}
\hline Linguistic scale for importance & TFN & Reciprocal TFN \\
\hline Just equal & $(1,1,1)$ & $(1 / 1,1 / 1,1 / 1)$ \\
Equal importance & $(1,1,3)$ & $(1 / 3,1 / 1,1 / 1)$ \\
Weak importance of one over & $(1,3,5)$ & $(1 / 5,1 / 3,1 / 1)$ \\
another & & \\
Moderately importance & $(3,5,7)$ & $(1 / 7,1 / 5,1 / 3)$ \\
Essential or strong importance & $(5,7,9)$ & $(1 / 9,1 / 7,1 / 5)$ \\
Very strong importance & $(7,9,10)$ & $(1 / 10,1 / 9,1 / 7)$ \\
Extremely preferred & $(9,10,10)$ & $(1 / 10,1 / 10,1 / 9)$ \\
\hline
\end{tabular}

Consider the object set $X=\left\{x_{1}, x_{2}, x_{3}, \ldots, x_{n}\right\}$ and the goal set $G=\left\{g_{1}, g_{2}, g_{3}, \ldots \ldots ., g_{n}\right\}$. Each object is taken and then the extent analysis for each goal is performed. In this way, $m$ extent analysis values for each TFNs object can be obtained:

$$
M_{g i}^{1}, M_{g i}^{2}, \ldots, M_{g i}^{m} \quad i=1,2, \ldots, n
$$

, where all $M_{g i}^{j}(j=1,2, \ldots, m)$ are TFNs representing the performance of object $x_{i}$ with regard to each goal $g_{j}$.

Step 2: Calculating the fuzzy synthetic extent value

In this step, the fuzzy synthetic extent value $\left(S_{i}\right)$ with respect to the $i_{\text {th }}$ criterion is calculated:

$$
S_{i}=\sum_{j=1}^{m} M_{g i}^{j} \otimes\left[\sum_{i=1}^{n} \sum_{j=1}^{m} M_{g i}^{j}\right]^{-1}
$$

To obtain $\sum_{j=1}^{m} M_{g i}^{j}$ in the Eq. (1), the fuzzy addition operation $m$ extent analysis values are performed for a particular matrix such that:

$$
\sum_{j=1}^{m} M_{g i}^{j}=\left[\sum_{j=1}^{m} l_{j}, \sum_{j=1}^{m} m_{j}, \sum_{j=1}^{m} u_{j}\right]
$$

, where $l$ is the smallest possible value, $m$ is the most promising value and $u$ is the largest possible value.

To obtain $\left[\sum_{i=1}^{n} l_{j} \sum_{j=1}^{m} m_{j} M_{g i}^{j}\right]^{-1}$ the fuzzy additional operation $M_{g i}^{j}(j=1,2, \ldots, m)$ values are performed as:

$$
\sum_{i=1}^{n} \sum_{j=1}^{m} M_{g i}^{j}=\left(\sum_{j=1}^{m} l_{j}, \sum_{j=1}^{m} m_{j}, \sum_{j=1}^{m} u_{j}\right)
$$

Then, inverse of the vector in the Eq. (3) is calculated as:

$$
\left[\sum_{i=1}^{n} \sum_{j=1}^{m} M_{g i}^{j}\right]^{-1}=\left(\frac{1}{\sum_{j=1}^{m} l_{j}}, \frac{1}{\sum_{j=1}^{m} m_{j}}, \frac{1}{\sum_{j=1}^{m} u_{j}}\right)
$$

Step 3: Calculating the degree of possibility

In this step the degree of possibility of $M_{1}=\left(l_{1}, m_{1}, u_{1}\right) \geq$ $M_{2}=\left(l_{2}, m_{2}, u_{2}\right)$ is defined as:

$$
V\left(M_{2} \geq M_{1}\right)=\mu_{M 2}(d)=\left\{\begin{array}{llc}
1, & \text { if } & m_{2} f m_{1} \\
0, & \text { if } & l_{1} \mathrm{p} u_{2} \\
\frac{l_{1}-u_{2}}{\left(m_{2}-u_{2}\right)-\left(m_{1}-l_{1}\right)}, & \text { otherwie }
\end{array}\right\}
$$

, where $d$ is the highest intersection point $\mu_{M 1}$ and $\mu_{M 2}$. To compare $M_{1}$ and $M_{2}$, both values $V\left(M_{1} \geq M_{2}\right)$ and $V$ $\left(M_{2} \geq M_{1}\right)$ are needed.

Step 4: Calculating the weight vectors

The degree possibility for a convex fuzzy number to be greater than $k$ convex fuzzy numbers $M_{i}=(i=1,2, \ldots, k)$ can be defined using:

$V\left(M \geq M_{1}, M_{2}, \ldots, M_{\mathrm{k}}\right)=V\left[\left(M \geq M_{2}\right)\right.$ and $\ldots$ and $(M \geq$ $\left.M_{k}\right)=\min V\left(M \geq M_{i}\right), i=1,2, \ldots, k$

With considering $d^{\prime}\left(A_{i}\right)=\min V\left(S_{i} \geq S_{k}\right)$ for $k=1,2, \ldots, n$; $k \neq i$, the weight vector is calculated as:

$$
W^{\prime}=\left(d^{\prime}\left(A_{1}\right), d^{\prime}\left(A_{2}\right), \ldots, d^{\prime}\left(A_{n}\right)\right)^{T}
$$


, where $A_{i}=(i=1,2, \ldots, n)$ are $n$ elements. The normalized weight vector is calculated using the normalization as:

$W=\left(d\left(A_{1}\right), d\left(A_{2}\right), \ldots, d\left(A_{n}\right)\right)^{T}$

, where $W$ is the non-fuzzy weight number.

\section{Fuzzy FMEA}

FMEA is a well-known engineering technique for identifying and eliminating the potential failures, problems, error from design, process, and/or service of the system and used in a wide range of industries [10-12]. A system, design, process, or service may usually have multiple failure modes or causes and effects. In this situation, each potential failure mode or cause needs to be evaluated and prioritized in terms of their risks. Therefore, the most dangerous failure modes can be identified and corrected with top priority.

The traditional FMEA determines the risk priorities of failure modes through the RPN, which is calculated as follows:

$\mathrm{RPN}=O \times S \times D$,

, where $O$ and $S$ are the frequency and seriousness (effects) of the failure, and $D$ is the ability to detect the failure.

In the traditional RPN, the $S, O$ and $D$ risk evaluating values for each incident are defined by crisp point. In contrast to the traditional method, the fuzzy RPNs use fuzzy linguistic terms for risk prioritization. Furthermore, the risk evaluating values are generally assumed to be equally important in calculating the final RPN values. Therefore, using the fuzzy logic to directly work with linguistic terms should be taken to consider. In the fuzzy RPN evaluation, the membership function of each risk evaluating value is determined by interpreting the linguistic terms shown in Table II $[13,14]$.

TABLE II

FUZZY RATINGS FOR RANKING THE RISK EVALUATING VALUES $[13,14]$

\begin{tabular}{lllc}
\hline $\begin{array}{c}\text { Effect or } \\
\text { severity }(S)\end{array}$ & $\begin{array}{l}\text { Probability of } \\
\text { occurrence }(O)\end{array}$ & $\begin{array}{c}\text { Detection ability } \\
(D)\end{array}$ & Rating \\
\hline None & Almost never & Almost certain & $(1,1,2)$ \\
Very slight & Remote & Very high & $(1,2,3)$ \\
Slight & Slight & High & $(2,3,4)$ \\
Very low & Low & Moderately high & $(3,4,5)$ \\
Low & Moderately low & Moderate & $(4,5,6)$ \\
Moderate & Moderate & Low & $(5,6,7)$ \\
High & Moderately high & Very low & $(6,7,8)$ \\
Very high & High & Remote & $(7,8,9)$ \\
Serious & Very high & Very remote & $(8,9,10)$ \\
Hazardous & Almost certain & Almost impossible & $(9,10,10)$ \\
\hline
\end{tabular}

After calculating the RPNs using the procedure mentioned above, the importance measure of each incidence, which has been calculated by FAHP, is integrated with the fuzzy RPNs as follows:

$$
\text { FRPN }{ }_{\text {Overall }}^{f}=W_{f} \times F R P N_{f}
$$

, where FRPN $f_{\text {Overall }}^{f}$ is the overall fuzzy RPN for failure mode $f, W$ is the non-fuzzy weight and FRPN is the fuzzy risk priority number.

In this way, the failure rates for each failure mode that might lead to an undesired system state is defined. Therefore, the decision makers will be able to detect the parts or processes of system that need to be in the priority of the maintenance activities [15].

\section{RESULTS}

This section is devoted to calculate the overall fuzzy RPN to prioritize the main failure modes of the rolling stocks. Rolling stock and Infrastructure are two main systems of each railway. Signal and power supply and rail tracks are the main parts of Infrastructure. While, all vehicles that move on a rail track (e.g. coaches, wagons and locomotives) refers to the rolling stock. Rolling stock can be classified as the most important system of railway. The primary failure data of LKAB Malmtrafik [16] shows that wheel set is the most critical subsystem of rolling stocks due to the highest number of failure and also its maintenance cost. Wheel sets, wheel tires or steel hoops, disk break, roller bearing, axle guide and oil pipe lines, as shown in Fig. 1 [17], are the main parts/items of the wheel set subsystems in the bogie frame.

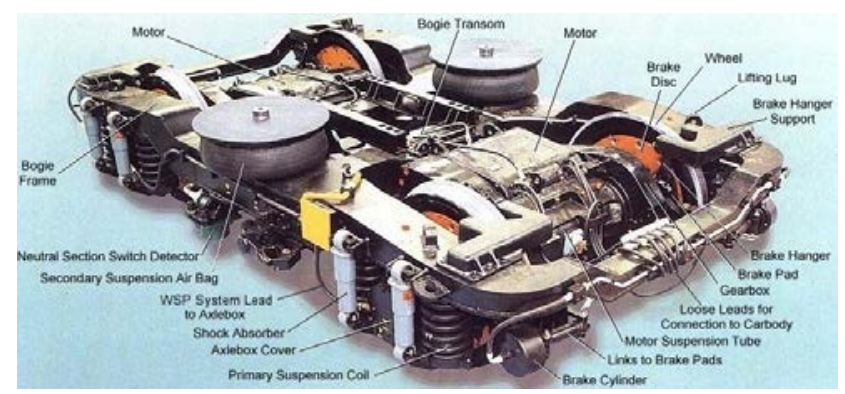

Fig. 1. Different parts of the wheel set subsystem in the bogie frame [17]

With studding the technical reports and the failure historical data, the main potential failure modes for different components can be defined. In this stage, the specific function and performance of the different components of system is developed and illustrated. The failure modes, corresponds to main component of wheel set subsystem, are summarized in Table III.

In the first step of AHP method, the group of decision makers used the linguistic variables (Table I) to obtain the triangular fuzzy judgment matrix. This matrix is given in Table IV. After creating the fuzzy judgment matrix, the fuzzy synthetic extent values $\left(S_{i}\right)$ are calculated from the Eq. (1) for each incident:

$$
\begin{aligned}
& S_{F 1}=(0.047,0.135,0.340), S_{F 2}=(0.057,0.138,0.446), \\
& S_{F 3}=(0.009,0.024,0.049), S_{F 4}=(0.029,0.072,0.186), \\
& S_{F 5}=(0.018,0.046,0.146), S_{F 6}=(0.041,0.103,0.272), \\
& S_{F 7}=(0.012,0.033,0.073), S_{F 8}=(0.060,0.179,0.516), \\
& S_{F 9}=(0.021,0.052,0.160), S_{F 10}=(0.005,0.018,0.034), \\
& S_{F 11}=(0.066,0.199,0.520) .
\end{aligned}
$$


TABLE III

THE FAILURE MODES OF DIFFERENT COMPONENT

\begin{tabular}{llc}
\hline Component & Failure mode & Code \\
\hline Bearing housing & $\begin{array}{l}\text { Tolerance and clearance of } \\
\text { bearing }\end{array}$ & $F 1$ \\
Wheel tire (steel hoop) & Wheel tire flat & $F 2$ \\
Pipelines (exhausters and & Oil leakage & $F 3$ \\
compressors) & Tire profile clearance & $F 4$ \\
Wheel tire & Wheel disc broken & $F 5$ \\
Wheel disc & High temperature & $F 6$ \\
Roller bearing & Axle sleeve broken & $F 7$ \\
Sleeve of axle & Wheel profile erosion & $F 8$ \\
Wheel tire & High temperature & $F 9$ \\
Wheel bearing & Loose screw & $F 10$ \\
Nuts and connections & Crack and flat spots & $F 11$ \\
Wheel set axles & & \\
\hline
\end{tabular}

Accordingly, the possibility degree of each pairwise failure mode is calculated from the Eq. (5).

Regarding the degree of possibility, the normalized importance weight of the failure modes is calculated using Eq.s (6) and (7):

$W_{F 1}=0.145, W_{F 2}=0.155, W_{F 3}=0.000, W_{F 4}=0.087$,

$W_{F 5}=0.062, W_{F 6}=0.122, W_{F 7}=0.008, W_{F 8}=0.172$,

$W_{F 9}=0.070, W_{F 10}=0.00, W_{F 11}=0.179$.
To calculate the risk evaluation factors $S, O$ and $D$, some questionnaires about the severity level, frequency and also the detection ability of each failure modes were prepared and sent out to the member of the decision making group. A sample questionnaire to calculate the severity factor is given in Fig. 2. In this way, the severity, occurrence and detectability of each failure mode were calculated based on the TFNs, as shown in Table V.

After calculating the fuzzy RPN, the overall fuzzy RPN was calculated with considering the importance measure of failure modes, obtained from FAHP and given in Table VI. For defuzzification of the FRPNs, the Graded Mean Intergraded (GMI), Centre of Gravity (CoG) and Bisector of Area (BoA), as the most frequency defuzzification methods, were used. The results are given in Table VI. According to Table VI, the failure modes F11, F8, F2, $F 1, F 6, F 4, F 9, F 5, F 7, F 3$ and $F 10$ are prioritized, respectively. On the other hand the maintenance inspections and activities should be focused on parts/items with the highest RPN.

TABLE IV

THE TRIANGULAR FUZZY JUDGMENT MATRIX

\begin{tabular}{lllllll}
\hline & \multicolumn{1}{c}{$F 1$} & \multicolumn{1}{c}{$F 2$} & \multicolumn{1}{c}{$F 3$} & \multicolumn{1}{c}{$F 4$} & \multicolumn{1}{c}{$F 5$} & $F 6$ \\
\hline$F 1$ & $(0.10,0.10,0.10)$ & $(0.700,0.978,1)$ & $(3.33,4.889,10)$ & $(1.433,1.833,3.33)$ & $(2,2.750,3.333)$ & $(1.111,1.294,2)$ \\
$F 2$ & $(1,1.023,1.430)$ & $(0.10,0.10,0.10)$ & $(3.333,5,10)$ & $(1.433,1.875,10)$ & $(2,2.813,10)$ & $(1.111,1.324,2)$ \\
$F 3$ & $(0.1,0.205,0.3)$ & $(0.10,0.20,0.3)$ & $(0.10,0.10,0.10)$ & $(0.3,0.375,0.5)$ & $(0.5,0.563,0.700)$ & $(0.1,0.265,0.3)$ \\
$F 4$ & $(0.3,0.545,0.7)$ & $(0.1,0.533,0.7)$ & $(2,2.667,3.33)$ & $(0.10,0.10,0.10)$ & $(1.433,1.5,3.333)$ & $(0.5,0.706,0.9)$ \\
$F 5$ & $(0.3,0.364,0.5)$ & $(0.1,0.356,0.5)$ & $(1.43,1.778,2)$ & $(0.3,0.667,0.7)$ & $(0.10,0.10,0.10)$ & $(0.3,0.471,0.5)$ \\
$F 6$ & $(0.5,0.773,0.9)$ & $(0.5,0.756,0.9)$ & $(3.33,3.778,3.78)$ & $(1.111,1.417,2)$ & $(2,2.125,3.33)$ & $(0.10,0.10,0.10)$ \\
$F 7$ & $(0.1,0.273,0.5)$ & $(0.1,0.267,0.3)$ & $(1.11,1.333,2)$ & $(0.3,0.5,0.7)$ & $(0.3,0.750,0.9)$ & $(0.1,0.353,0.50)$ \\
$F 8$ & $(1.111,1.314,2)$ & $(1.11,1.284,1.43)$ & $(3.33,6.422,10)$ & $(2,2.408,10)$ & $(3.333,3.613,10)$ & $(1.43,1.7,3.333)$ \\
$F 9$ & $(0.3,0.409,0.5)$ & $(0.3,0.4,0.7)$ & $(1.433,2,3.33)$ & $(0.5,0.75,0.9)$ & $(1,1.125,2)$ & $(0.3,0.529,0.7)$ \\
$F 10$ & $(0.1,0.159,0.3)$ & $(0.1,0.156,0.3)$ & $(0.5,0.778,0.9)$ & $(0.1,0.292,0.3)$ & $(0.1,0.438,0.5)$ & $(0.1,0.206,0.3)$ \\
$F 11$ & $(1.430,1.459,2)$ & $(1.11,1.427,1.43)$ & $(3.333,7.133,10)$ & $(2,2.675,10)$ & $(3.333,4.013,10)$ & $(1.43,1.88,3.33)$ \\
\hline & \multicolumn{1}{c}{$F 7$} & $F 8$ & \multicolumn{1}{c}{$F 9$} & \multicolumn{1}{c}{$F 10$} & $F 11$ & \\
\hline$F 1$ & $(2,3.667,10)$ & $(0.5,0.761,0.9)$ & $(2,2.444,3.33)$ & $(3.333,6.286,10)$ & $(0.5,0.686,0.7)$ & \\
$F 2$ & $(3.333,3.75,10)$ & $(0.7,0.779,0.9)$ & $(3.333,2.5,3.333)$ & $(3.333,6.429,10)$ & $(0.7,0.701,0.9)$ & \\
$F 3$ & $(0.5,0.750,0.9)$ & $(0.1,0.156,0.3)$ & $(0.3,0.5,0.7)$ & $(1.111,1.286,2)$ & $(0.1,0.140,0.3)$ & \\
$F 4$ & $(1.433,2,3.333)$ & $(0.1,0.415,0.5)$ & $(1.11,1.333,1.11)$ & $(3.333,3.429,10)$ & $(0.1,0.374,0.5)$ & \\
$F 5$ & $(1.11,1.333,3.33)$ & $(0.1,0.277,0.3)$ & $(0.5,0.889,1)$ & $(2,2.286,10)$ & $(0.1,0.249,0.3)$ & \\
$F 6$ & $(2,2.833,10)$ & $(0.3,0.588,0.7)$ & $(1.43,1.889,3.33)$ & $(3.333,4.857,10)$ & $(0.3,0.530,0.7)$ & \\
$F 7$ & $(0.10,0.10,0.10)$ & $(0.1,0.208,0.3)$ & $(0.5,0.667,0.7)$ & $(1.429,1.714,3.333)$ & $(0.1,0.187,0.3)$ & \\
$F 8$ & $(3.333,4.817,10)$ & $(0.10,0.10,0.10)$ & $(2,3.211,10)$ & $(3.333,8.257,10)$ & $(0.70,0.900,1)$ & \\
$F 9$ & $(1.433,1.500,2)$ & $(0.1,0.311,0.5)$ & $(0.10,0.10,0.10)$ & $(2,2.571,10)$ & $(0.1,0.280,0.3)$ & \\
$F 10$ & $(0.3,0.583,0.700)$ & $(0.1,0.121,0.3)$ & $(0.1,0.389,0.5)$ & $(0.10,0.10,0.10)$ & $(0.1,0.109,0.3)$ & \\
$F 11$ & $(3.333,5.350,10)$ & $(1,1.111,1.430)$ & $(3.333,3.567,10)$ & $(3.33,9.171,10)$ & $(0.10,0.10,0.10)$ & \\
\hline
\end{tabular}

Dear expert

What do you think about the severity degree of each failure mode in rolling stocks operation?

Please, check $\otimes$ for the appropriate response bellow.

\begin{tabular}{|l|c|c|c|c|c|c|c|c|c|c|}
\hline \multicolumn{1}{|c}{ Failure mode } & \multicolumn{9}{|c|}{ Severity degree } \\
\cline { 2 - 11 } & None & $\begin{array}{c}\text { Very } \\
\text { slight }\end{array}$ & Slight & $\begin{array}{c}\text { Very } \\
\text { low }\end{array}$ & Low & Moderate & High & $\begin{array}{c}\text { Very } \\
\text { high }\end{array}$ & Serious & Hazardous \\
\hline Tolerance and clearance of bearing & $\square$ & $\square$ & $\square$ & $\square$ & $\square$ & $\square$ & $\square$ & $\square$ & $\square$ & $\square$ \\
\hline Wheel tire flat & $\square$ & $\square$ & $\square$ & $\square$ & $\square$ & $\square$ & $\square$ & $\square$ & $\square$ & $\square$ \\
\hline Oil leakage & $\square$ & $\square$ & $\square$ & $\square$ & $\square$ & $\square$ & $\square$ & $\square$ & $\square$ & $\square$ \\
\hline Tire profile clearance & $\square$ & $\square$ & $\square$ & $\square$ & $\square$ & $\square$ & $\square$ & $\square$ & $\square$ & $\square$ \\
\hline Wheel disc broken & $\square$ & $\square$ & $\square$ & $\square$ & $\square$ & $\square$ & $\square$ & $\square$ & $\square$ & $\square$ \\
\hline High temperature & $\square$ & $\square$ & $\square$ & $\square$ & $\square$ & $\square$ & $\square$ & $\square$ & $\square$ & $\square$ \\
\hline Axle sleeve broken & $\square$ & $\square$ & $\square$ & $\square$ & $\square$ & $\square$ & $\square$ & $\square$ & $\square$ & $\square$ \\
\hline Wheel profile erosion & $\square$ & $\square$ & $\square$ & $\square$ & $\square$ & $\square$ & $\square$ & $\square$ & $\square$ & $\square$ \\
\hline High temperature & $\square$ & $\square$ & $\square$ & $\square$ & $\square$ & $\square$ & $\square$ & $\square$ & $\square$ & $\square$ \\
\hline Loose screw & $\square$ & $\square$ & $\square$ & $\square$ & $\square$ & $\square$ & $\square$ & $\square$ & $\square$ & $\square$ \\
\hline Crack and flat spots & $\square$ & $\square$ & $\square$ & $\square$ & $\square$ & $\square$ & $\square$ & $\square$ & $\square$ & $\square$ \\
\hline
\end{tabular}

Fig. 2. A sample questionnaire for calculating the severity degree of each failure mode 
TABLE V

THE TRIANGULAR FUZZY JUDGMENT MATRIX

\begin{tabular}{cccccccc}
\hline Failure mode & Severity $(S)$ & Occurrence $(O)$ & Detection $(D)$ & Failure mode & Severity $(S)$ & Occurrence $(O)$ & Detection $(D)$ \\
\hline$F 1$ & $(0.3,0.630,0.7)$ & $(0.1,0.420,0.7)$ & $(0.7,0.900,1.0)$ & $F 7$ & $(0.5,0.700,0.9)$ & $(0.0,0.300,0.7)$ & $(0.1,0.460,0.7)$ \\
$F 2$ & $(0.3,0.620,0.9)$ & $(0.3,0.600,0.9)$ & $(0.3,0.660,0.9)$ & $F 8$ & $(0.5,0.760,1.0)$ & $(0.1,0.440,0.7)$ & $(0.7,0.930,1.0)$ \\
$F 3$ & $(0.1,0.430,0.7)$ & $(0.0,0.260,0.5)$ & $(0.3,0.650,0.9)$ & $F 9$ & $(0.3,0.500,0.9)$ & $(0.1,0.340,0.7)$ & $(0.3,0.700,1.0)$ \\
$F 4$ & $(0.3,0.540,0.9)$ & $(0.3,0.600,0.9)$ & $(0.1,0.440,0.7)$ & $F 10$ & $(0.1,0.500,0.7)$ & $(0.0,0.240,0.5)$ & $(0.1,0.430,0.7)$ \\
$F 5$ & $(0.1,0.320,0.7)$ & $(0.1,0.400,0.7)$ & $(0.5,0.820,1.0)$ & $F 11$ & $(0.3,0.620,0.7)$ & $(0.5,0.820,1.0)$ & $(0.5,0.720,1.0)$ \\
$F 6$ & $(0.1,0.350,0.7)$ & $(0.5,0.720,1.0)$ & $(0.5,0.830,1.0)$ & & & & \\
\hline
\end{tabular}

After calculating the fuzzy RPN, the overall fuzzy RPN was calculated with considering the importance measure of failure modes, obtained from FAHP and given in Table VI. For defuzzification of the FRPNs, the Graded Mean Intergraded (GMI), Centre of Gravity (CoG) and Bisector of Area (BoA), as the most frequency defuzzification methods, were used. The results are given in Table VI. According to Table VI, the failure modes $F 11, F 8, F 2$, $F 1, F 6, F 4, F 9, F 5, F 7, F 3$ and $F 10$ are prioritized, respectively. On the other hand the maintenance inspections and activities should be focused on parts/items with the highest RPN.

TABLE VI

THE FRPN AND OVERALL FRPN FOR EACH FAILURE MODE

\begin{tabular}{ccccc}
\hline Failure modes & $F R P N_{\text {overal }}$ & GMI & CoG & BoA \\
\hline$F 1$ & $(0.003,0.034,0.071)$ & 0.035 & 0.036 & 0.036 \\
$F 2$ & $(0.004,0.038,0.112)$ & 0.045 & 0.052 & 0.048 \\
$F 3$ & $(0.000,0.000,0.000)$ & 0.000 & 0.000 & 0.000 \\
$F 4$ & $(0.001,0.012,0.049)$ & 0.017 & 0.021 & 0.019 \\
$F 5$ & $(0.000,0.006,0.030)$ & 0.009 & 0.012 & 0.011 \\
$F 6$ & $(0.003,0.025,0.086)$ & 0.032 & 0.038 & 0.035 \\
$F 7$ & $(0.000,0.001,0.003)$ & 0.001 & 0.001 & 0.001 \\
$F 8$ & $(0.006,0.053,0.120)$ & 0.057 & 0.060 & 0.058 \\
$F 9$ & $(0.001,0.008,0.044)$ & 0.013 & 0.018 & 0.015 \\
$F 10$ & $(0.000,0.000,0.000)$ & 0.000 & 0.000 & 0.000 \\
$F 11$ & $(0.013,0.066,0.126)$ & 0.067 & 0.068 & 0.068 \\
\hline
\end{tabular}

\section{CONCLUSIONS}

FMEA technique provides suitable information for making risk management decisions. In this paper, the Risk Priority Number technique was used to prioritize the rolling stock failure modes. To fine the importance degree of each failure mode, the AHP method was applied. All calculations were done in the fuzzy environment to reduce the uncertainties. Results of this study show that, the crack and flat spots of wheels and axles, profile erosion of wheel and wheel tire flat are the most hazardous failure modes which need to be under special consideration during the maintenance activities.

\section{ACKNOWLEDGMENT}

The authors would like to thank for the support of JVTC (Luleå Railway Research Center) and CAMM (Centre of Advanced Mining \& Metallurgy) projects in this research work.

\section{REFERENCES}

[1] Seo SI, Park CS, Choi SH, Han YJ, Kim KH. 2010. "Reliability management and assessment for the electric traction system on the Korea High-Speed Train". Proceedings of the Institution of Mechanical Engineers, Part F: Journal of Rail and Rapid Transit, 224(3), 179-188.
[2] Conradie P, Treurnicht N. (2012, June). "Exploring critical failure modes in the rail environment and the consequential costs of unplanned maintenance". In Computers and Industrial Engineering 42.

[3] Fourie CJ, Vlok PJ, Treurnicht NF. 2015. "Quantifying system reliability in rail transportation in an ageing fleet environment”. South African Journal of Industrial Engineering, 26(2), pp. 128-142.

[4] Rahimdel MJ, Bagherpour R. 2018. "Haulage system selection for open pit mines using fuzzy MCDM and the view on energy saving". Neural Computing and Applications, 29(6), pp. 187-199.

[5] Zadeh LA. 1965. “Fuzzy sets”. Inf Control 8, pp. 338-353.

[6] Rahimdel MJ, Karamoozian M. 2014. "Fuzzy TOPSIS method to primary crusher selection for Golegohar Iron Mine (Iran)”. Journal of Central South University, 11(21), pp. 4352-4359.

[7] Saaty T. 1980. "The Analytic hierarchy presses: planning, priority setting, resource allocation”. New York: McGrawHill.

[8] Rahimdel MJ, Ataei M. 2014. "Application of analytical hierarchy process to selection of primary crusher". International Journal of Mining Science and Technology, 24(4), pp. 519-523.

[9] Chang DY. 1996. "Applications of the extent analysis method on fuzzy AHP”. Eur J Oper Res 95, pp. 649-655.

[10] Stamatis D.H. 1995. "Failure mode and effect analysis: FMEA from theory to execution”. Milwaukee, WI: ASQC Quality Press.

[11] Su XY, Deng Y, Mahadevan S, Bao QL. 2012. “An Improved Method for Risk Evaluation in Failure Modes and Effects Analysis of Aircraft Engine Rotor Blades". Engineering Failure Analysis, 26, pp. 164-174, doi: 10.1016/j.engfailanal.2012.07.009.

[12] Chang KH, Cheng CH. 2011. "Evaluating the Risk of Failure Using the Fuzzy OWA and DEMATEL Method". Journal of Intelligent Manufacturing, 22, pp. 113-129. doi: 10.1007/s10845-009-0266-X.

[13] Zhang Z, Chu X. 2011. "Risk prioritization in failure mode and effects analysis under uncertainty”. Expert Systems with Applications, 38(1), pp. 206-214.

[14] Xu K, Tang TC, Xie M, Ho SL, Zhu ML. 2002. "Fuzzy assessment of FMEA for engine systems". Reliability Engineering \& System Safety, 75, pp. 17-29.

[15] Ericson CA. 2005. "Hazard Analysis Techniques for System Safety”. John Wiley \& Sons, Inc. Chapter 13, pp. 235-259.

[16] LKAB Malmtrafik, the Swedish railway company, https://www.lkab.com/en/.

[17] The Railway Technical Website, adapted in 2018, http://www.railway-technical.com/trains/rolling-stockindex-l/bogies.html. 